\title{
Discontinuance among California's electric vehicle buyers: Why are some adopters abandoning electric vehicles?
}

Scott Hardman ( $\sim$ shardman@ucdavis.edu )

University of California, Davis

Gil Tal

University of California, Davis https://orcid.org/0000-0001-7843-3664

\section{Article}

Keywords: PEVs, Discontinuance, Convenience of Charging

Posted Date: September 8th, 2020

DOI: https://doi.org/10.21203/rs.3.rs-66378/v1

License: (c) (1) This work is licensed under a Creative Commons Attribution 4.0 International License.

Read Full License

Version of Record: A version of this preprint was published at Nature Energy on April 26th, 2021. See the published version at https://doi.org/10.1038/s41560-021-00814-9. 


\section{Abstract}

For the market share of plug-in electric vehicles (PEVs) to continue to increase and reach $100 \%$ of the market, adopters of the technology, who initially buy PEVs, will need to continue choosing them in subsequent purchases. While much research has focused on the reasons for and barriers to initial PEV adoption, less has been devoted to the reasons for discontinuance-abandoning a new technology after first adopting it. Based on results from five questionnaire surveys, we find that PEV discontinuance in California occurs at a rate of $21 \%$ for plug-in hybrid vehicle adopters and $17 \%$ for battery electric vehicle adopters. We show that discontinuance is related to dissatisfaction with the convenience of charging, having preferences for vehicles with lower energy efficiencies, being a later adopter, not having level 2 (220-volt) charging from home, and not being male.

\section{Introduction}

For any new product to achieve a $100 \%$ market penetration, early adopters must make initial purchases and continue to purchase the technology whenever they replace their initial purchase or buy additional products. Plug-in electric vehicles (PEVs), which include battery electric vehicles (BEVs) and plug-in hybrid electric vehicles (PHEVs), have had a growing market share in many nations since 2012. In California, the region of analysis in this study, PEVs reached $10 \%$ market share in 2019 , and in Norway, the country with the largest PEV market share, the vehicles reached over $50 \%$ in 2019. California, Norway, and several other nations have goals of reaching 100\% electric vehicle sales by 2025 (Norway), 2030 (Denmark, Ireland, India), and 2040 (California, UK, France) [1]. These goals may become impossible to achieve, as evidence from California indicates that some early adopters are discontinuing PEV ownership in favour of conventional vehicles.

Most published research on PEV market penetration and consumer choice focuses on initial adoption and characteristics of early adopters. To our knowledge, there are no published reports on PEV discontinuance-i.e., when an adopter no longer owns or uses the technology they originally adopted [2]. The aim of this study is to understand why PEV adopters in California are discontinuing PEV ownership. To do this we use results from five questionnaire surveys, conducted between 2015 and 2019. The first four surveys are cohort surveys of PEV buyers, in the final survey respondents are recruited form the first four surveys. We construct logistic regression models to assess the correlation of various factors with the likelihood of discontinuing ownership of a BEV or PHEV.

Though the literature does not include studies on PEV discontinuance, insights on who is buying PEVs, the barriers to adoption, and purchase motivations are still useful for this study. The decision to discontinue PEV adoption could be related to the sociodemographic profile of consumers, their perceptions of PEVs, and perceived barriers to PEV adoption. Early studies used stated preference methods with surveys of general population to identify PEV adopters [3,4,13-18,5-12]. These studies typically found that those most likely to purchase a PEV tended to be male and have a high household income, a high level of education, and multiple vehicles in the household. More recent research gathered 
data from consumers who had purchased a PEV. Studies in Sweden, Norway, the United States, and Canada are consistent in finding PEV buyers are mostly male, middle aged, with mid to high household income, and highly educated [19-23]. Several studies [7,23,25-29] identified a relationship between proenvironmental attitudes and positive perceptions of PEVs. Having pro-technology lifestyles or identifying as an innovator is also related to PEV adoption or adoption intent [25,29], as is having preferences for vehicles with higher efficiencies [24].

Reasons for PEV purchase include environmental motivations [30-36] and low running and ownership costs-especially related to refuelling, but also to maintenance costs $[7,30,36,37]$. The high performance and rapid acceleration of PEVs can be a purchase motivator [38], especially among those who have already adopted a PEV [35]. Reasons for adoption also include wanting to be the first to adopt a new technology or novelty seeking $[31,35,36]$, which is related to having pro-technology attitudes. PEV buyers are also encouraged to buy the vehicles through direct incentives, such as grants, rebates, and tax credits [40], and through indirect incentives, such as free or discounted parking, access to bus or carpool lanes, and toll fee waivers [41].

Studies on barriers to PEV adoption, regardless of their region of analysis, seem to be consistent in finding some combination of range, purchase price, driving range, model availability, and lack of infrastructure are the most substantial barriers to adoption [4,34,42-48]. Some suggest limited driving range is the largest barrier $[4,46]$, while others suggest is it purchase price $[43,45]$ or the availability of charging [49].

The factors related to PEV adoption or non-adoption could be related to the decision to continue or discontinue PEV ownership. We therefore use these insights from the literature to inform out study.

\subsection{Introduction to Discontinuance}

We investigate discontinuance among those who no longer own their original PEV and now own a newer vehicle. We exclude those who still own their original PEV (unless they purchased the vehicle at the end of the lease period). We exclude these households because they have not reached a decision point and may or may not be planning to continue with PEV ownership. Leaving these out of the analysis is important, as we do not know whether their attitudes, satisfaction with their vehicle, or any other factors are representative of someone who is planning to abandon PEVs or continue owning one. If a BEV adopter purchased a PHEV after owning a BEV initially (or vice versa) this qualifies as continuing PEV ownership. Discontinuance occurs only when a BEV or PHEV adopter no longer owns any PEV and now owns an internal combustion engine vehicle or hybrid electric vehicle.

Figure 1 shows the percent of PHEV and BEV adopters who discontinued PEV ownership in the sample and the weighted percent (see Appendix 1 for weights). Figure 2 shows discontinuance between common PEV makes in the sample. The highest rate of discontinuance is among those who adopted a Fiat PEV, and the lowest is among those who adopted a Tesla PEV. 


\section{Methods}

\subsection{Questionnaire Surveys}

The five questionnaire surveys conducted between 2015 and 2019 include four cohort surveys and a final survey where respondents are recruited form the first four surveys. We refer to responses to the first four surveys as 'survey 1 ' since this was the first survey respondents took, we refer to responses to the fifth survey as 'survey 2' since this was the second survey respondents participated in. The initial questionnaire surveys were conducted in 2015, 2016, 2017, and 2018. These surveys recruited households in California who purchased a PEV between 2012 and 2018. The California Air Resources Board helped in recruitment by sending survey invites to households who applied for a California Clean Vehicle Rebate. The final fifth survey was conducted in December 2019. Households who indicated at the end the survey 1 that they are willing to participate in future studies were sent an email inviting them to take this survey.

The first four surveys were mostly concerned with understanding PEV adopters in California [50], their charging behaviour [51], and the impact of incentives on the decision to purchase a PEV [52]. The surveys contained the following sections:

- Household information including number of vehicles in the household, number of people in the household, age and gender of household members, household income, home type (e.g., single family home or multi-unit dwelling), home ownership.

- Information on household vehicles including make, model, year of purchase, and odometer readings.

- Electric vehicle charging behaviour, including location of charging (e.g., home, work, or public charging station).

- Travel behaviour questions, including home and work locations, which are used to determine commute distance, and information on long-distance trips.

- The importance of incentives in the decision to purchase a PEV, including the US Federal tax credit, California Clean Vehicle Rebate, High Occupancy Vehicle (HOV) lane access, and other local incentives (e.g., from utilities).

The final survey contained the same sections as previous surveys but added the following sections which were designed to help understand subsequent purchase behaviour of PEV adopters. These included:

- Questions on satisfaction with vehicle attributes for their previously owned PEV in the following areas: safety, comfort, refuelling/recharging costs, performance, environmental impacts, vehicle purchase price (including rebates, discounts, etc.), reliability, electric driving range, convenience of charging, and driving assistance features.

- Twenty-two lifestyle statements which are used to generate lifestyle factors (see Appendix 3). 
The final survey was sent to 14,128 household who had previously participated in one of the four original surveys. Of these, 4925 started the survey, and 4167 completed it. Households who still own their original PEV are not included in the study. This leaves 1842 responses who

no longer own their original PEV and either own a newer PEV or do not own any PEV. Discontinuance in this sample of 1842 is $20.85 \%$ ( 384 households), while $79.15 \%$ (1458 households) continue to own a PEV. Of those that continued with PEV ownership, 245 purchased their PEV at the end of the lease period, and 1213 now own a different PEV. The 384 households who discontinued PEV ownership own no plug-in vehicles in their household.

\subsection{Attitudinal and lifestyle factors}

Since attitudes and lifestyle have a relationship with PEV adoption [7,23-29], we included a section with 22 attitudinal and lifestyle statements with which respondents could strongly disagree, slightly disagree, neither agree nor disagree, slightly agree, or strongly agree. We employ maximum likelihood factor analysis as a data reduction technique to reduce these 22 variables to a smaller number of variables to be used in regression analysis. Appendix 2 shows a table of these 8 factors and the factor loadings for each of the 22 questions. The factors have the following characteristics:

- Commuting in congestion, stressful commute: Having the belief that commuting is stressful, traffic congestion is a problem, that commuting is time wasted, and disagreeing that their commute is pleasant.

- Like Suburban Living: Wanting to live in a spacious house, liking the idea of a large yard and plenty of space between houses, and not desiring to live near transit.

- Outdoor lifestyle: Enjoying having an outdoor lifestyle and travelling to outdoor destinations.

- Enjoy shopping in stores: Preferring shopping in stores rather than shopping online.

- Exercise not important: Belief that exercise isn't important and the importance of it is overrated.

- Pro-technology: Liking to be among the first to have the latest technology and liking to try new and different things.

- Having children means need a car, like routine: Belief that having children means you need a car and liking sticking to a routine.

- Congestion is a problem, try to make use of time travelling: Believing traffic congestion is a problem and trying to make the best use of time spent travelling.

\subsection{Binary Logistic Regression}

We estimate four models to understand discontinuance, two for BEVs only, and two for PHEVs only. We estimate separate models for BEVs and PHEVs because the vehicles are different in key areas, most notably their driving range and refuelling/recharging requirements. This may mean the reasons for 
discontinuance of a BEV or a PHEV diverge. We estimate two model for each PEV type; one includes PHEV or BEV electric driving range, and another that includes a measure of respondents satisfaction with the driving range of their PHEV or BEV. For the results to be representative of the PEV market we weight the model based on the proportion of PEV makes in the market for the years of the initial PEV purchase in our sample (2012-2018). We do this because some automakers are underrepresented in the sample (e.g. Tesla), while others are overrepresented (e.g. Nissan). The weights are shown in Appendix 3.

The models include socio-demographic variables that are commonly correlated with PEV adoption or adoption intention [34,50]. We also include changes in some demographics since a change in a household's circumstances could be related to discontinuance, for example a change in the number of people in the household. Lifestyle variables are included, as studies show attitudes and lifestyles (e.g., pro-technology attitudes), not just sociodemographic variables, are correlated with interest in PEVs. For charging we include respondents' access to charging at home, including the level they have access to as a categorical variable (no charging, Level 1, or Level 2). For workplace charging we include a dummy variable for whether they have access to any charging at work (Level 1, Level 2, DCFC). For public charging we include a dummy variable for whether respondents have used level 2 or DCFC charging, we exclude level 1 charging from this since the utility derived from charging at a Level 1 charger in public is minimal. We include variables on how satisfied consumers were with their PEV across various attributes. Vehicle attributes are common barriers to adoption (e.g., range) $[4,30,46,47,31-34,42-45]$. Year of PEV adoption is included as prior studies have identified changes to PEV adopters over time [50,52]. Early buyers of PEVs are more likely to be innovators compared to later buyers, which may have a relationship with interest in continuing PEV adoption. The models contain the following variables:

- Sociodemographic Variables: Age of survey taker, Gender (1 male, 0 other) of survey taker, Highest level of education of survey taker, Vehicle Ownership (1 lease, 0 other), Change in number of people (from Survey 1 to Survey 2), Home type (detached 1, other 0 )

- Charging variables: A categorical variable for whether respondents have charging at home (No Charging, Level 1, Level 2), whether respondents have charging at work (1 yes, 0 no), whether respondents use public Level 2 or DC Fast Charging (1 yes, 0 no).

- Travel variables: Commute distance, Number in trips over 200 miles.

- Household Vehicle Variables: efficiency of the second vehicle in the household (in EPA MPG), BEV (or PHEV) electric driving range, Change in number of vehicles (from Survey 1 to Survey 2).

- Respondent satisfaction with the following attributes of their PEV: Safety, Vehicle Purchase Price, Reliability, Convenience of charging, Refueling/Recharging costs, and Electric driving range.

- Pro-technology lifestyle factor.

- Year the PEV was adopted.

We exclude several variables due to multicollinearity. We exclude the following: annual vehicle miles travelled (VMT), since it is correlated with commute distance; 5 of the 10 vehicle satisfaction measures (satisfaction with comfort, performance, environmental impacts, and driving assistance features are 
excluded); home ownership, since it is correlated with home type. We also only include one lifestyle factor (pro-technology). Initially we had to exclude 'Like Suburban Living' and 'Having children means need a car, like routine' as they correlated with the Pro-technology factor. This left 6 factors in the model, however the only factor with a link with PEV adoption is the pro-technology one. Therefore, we include only this factor in the model because we do not wish to retain any other factors as control variables.

\section{Results}

First we explore the sociodemographic profile of households that discontinued PEV ownership in comparison to those that continued ownership, then we explore differences in their travel behaviour and any differences in their satisfaction with vehicle attributes. We also discuss charging behaviour and finally show the results for the models of BEV and PHEV discontinuance.

\subsection{Sociodemographic profile}

Table 5 (in Appendix 4) shows the number of people in the household, number of vehicles in the household, age, gender, household income, highest level of education, home type, and home ownership for those that discontinued or continued PEV adoption. Table 6 (Appendix 4) shows t-test comparisons for continuous variables and Table 7 (Appendix 4) shows chi-square tests for nominal variables. Of the 8 socio-demographic variables tested 7 are significantly different: households that discontinued PEV ownership have fewer people in the household, fewer vehicles in the household, are younger, have lower household incomes, fewer are males, more of them rent rather than own their home, and more live in a house that is not a single family home/detached house. Table 8 shows t-test results for respondents travel behaviour. Two significant differences exist, those that discontinued PEV ownership have lower annual vehicle miles travelled and shorter one-way commute distances.

\subsection{Satisfaction with previous PEV}

Survey respondents were asked to rate their previous PEV for 10 vehicle attributes. Figure 3 shows the distribution of responses for those who continued PEV ownership (top row) and those who discontinued PEV ownership (bottom row). We also compare the distribution of responses using chi-square tests (see Table 1). Respondents appear to be mostly satisfied with their PEVs safety, comfort, refuelling/recharging costs, performance, environmental impacts, purchase price, and reliability. Responses for electric driving range, convenience of recharging, and driving assistance features are more widely dispersed. Electric driving range is the only attribute where more respondents are dissatisfied than satisfied. The distributions are significantly different for safety, refuelling/recharging costs, reliability, electric driving range, and convenience of charging. For all of these attributes, those who discontinued adoption are less satisfied than those that continued adoption. 
Table 1: Chi-square test results comparing the distributions in Figure 3 for those who continued PEV ownership and those who discontinued PEV ownership $(*=<0.1, * *=<0.05, * * *=<0.01)$.

\begin{tabular}{|lllll|}
\hline & N & DF & $\begin{array}{l}\text { Pearson Chi- } \\
\text { Square }\end{array}$ & p-value \\
\hline Safety & 1672 & 4 & 10.378 & $0.0345^{\star \star}$ \\
\hline Comfort & 1672 & 4 & 4.96 & 0.2914 \\
\hline Refuelling/Recharging costs & 1672 & 4 & 11.954 & $0.0177^{\star \star}$ \\
\hline Performance & 1672 & 4 & 5.461 & 0.2432 \\
\hline Environmental Impacts & 1672 & 4 & 9.104 & $0.0586^{\star}$ \\
\hline $\begin{array}{l}\text { Vehicle Purchase Price (including rebates, discounts, } \\
\text { etc.) }\end{array}$ & 1672 & 4 & 6.857 & 0.1436 \\
\hline Reliability & 1672 & 4 & 11.228 & $0.0241^{\star \star}$ \\
\hline Electric driving range & 1672 & 4 & 11.181 & $0.0246^{\star \star}$ \\
\hline Convenience of charging & 1672 & 4 & 63.701 & $<0.001^{\star \star *}$ \\
\hline Driving assistance features & 1672 & 4 & 4.477 & 0.3452 \\
\hline
\end{tabular}

\subsection{Charging access}

Figure 4 shows differences in access to charging between those who continue vs. discontinue PEV ownership. Having no charging access at home is more common among respondents who discontinue rather than continue PEV ownership ( $28 \%$ vs. $14 \%$, Figure 4 ). Of those that continued ownership $50 \%$ have access to level 2 (220-Volt) charging at home, compared to only $29 \%$ of those that discontinued PEV ownership. Fewer households who discontinued ownership have access to charging at work. Of those that continued owning a PEV, 43\% have access to either DC Fast, Level 1, or Level 2 charging from work. Of those who discontinued ownership of a PEV, 36\% have access to DC Fast, Level 1, or Level 2 at home. Of those that continued PEV ownership, 59\% report no public charging, compared to $63 \%$ of those that discontinued ownership. More households who continued PEV ownership report using only Level 2 charging, though fewer report using Level 2 in combination with DC Fast Charging. Chi-square tests comparing these distributions shows workplace charging access and public charging use are not significantly different. The distributions for access to home charging are significantly different, with fewer households who no longer own a PEV having home charging, and of those that do have home charging, fewer have Level 2 charging. 


\subsection{Modelling BEV discontinuance}

Table 3 shows the results for the two BEV binary logistic regression models. The first model includes the variable satisfaction with $B E V$ driving range, and the second includes the actual electric driving range of adopters BEV based on the US EPA figures. The models show odds ratios for each variable, a value higher than one is correlated with increasing odds of discontinuing BEV ownership, a value less than one is correlated with decreasing odds of discontinuing BEV ownership.

In the model with BEV driving range, the change in number of vehicles in the household has an odds ratio of 0.655 , meaning a one unit increase in the number of vehicles in the household is correlated with $34.5 \%$ lower odds of discontinuing BEV ownership. This could be explained by households being less willing to own a BEV when they have fewer vehicles due to reduced flexibility from a limited range BEV compared to a conventional vehicle. Gender has an odds ratio of 0.478 indicating the odds of discontinuing adoption are $52.2 \%$ lower for male BEV adopters.

A 1 point increase in the satisfaction with the convenience of charging a BEV is correlated with a $15.8 \%$ decrease in odds of discontinuing BEV adoption. Those that no longer own a BEV to have less favourable attitudes to charging compared to those that continued ownership. A one unit increase in the MPG of the second vehicle in the household is correlated with a $3.8 \%$ decrease in odds of discontinuing BEV ownership. This could suggest that those who discontinue BEV ownership are less interested in energy efficient vehicles in general. Commute distance has an odds ratio of 0.982 , indicating a 1 mile increase in one-way commute distance correlated with $0.18 \%$ lower odds of discontinuing BEV adoption. Those who are discontinuing ownership have shorter commute distances than those who continue ownership. This could be because those with longer commutes perceive a greater financial benefit of continuing ownership of a BEV.

Having access to level 2 charging from home compared to level 1 charging at home decreases the odds of discontinuing ownership by $51.1 \%$. Having level 1 charging over no charging does not have any significant relationship with discontinuing BEV ownership. This shows the importance of having higher speed level 2 charging from home, over low speed level 1 charging. Level 2 rather than level 1 charging gives drivers greater utility and maximises the amount of travel they can do in a BEV. Furthermore, the installation of a level 2 charger at home is an investment that will not be used if BEV ownership were discontinued. Access to charging at work or the use of public chargers has no relationship with discontinuance. Finally, there is a positive relationship between the odds of discontinuing ownership and later BEV purchase year. This could be a result of earlier buyers of BEVs being enthusiastic about BEVs and later buyers being more pragmatic and perhaps being less willing to accept some of the differences of BEVs in comparison to ICEVs.

The second model, with satisfaction with BEV driving range rather than actual range (i.e. EPA range), finds the same variables to be significant with similar odds ratios. In this model BEV driving range is not significantly correlated with BEV discontinuance, indicating that satisfaction with range nor actual driving 
range correlate with the decision to discontinue BEV adoption. Satisfaction with the convenience of charging is no longer significant, showing that when controlling for EV range, the level of satisfaction with charging has no relationship with the decision to continue with BEV ownership.

Table 3: Binary logistic regression models for BEV discontinuance (where 1 = discontinued BEV ownership, 0 = continued BEV ownership). The table shows two models, one with Satisfaction with BEV range as an independent variable, and a second with BEV driving range $(*=<0.1, * *=<0.05, * \star *=<0.01)$. 


\begin{tabular}{|c|c|c|c|c|c|c|}
\hline \multirow[b]{2}{*}{ Term } & \multicolumn{3}{|c|}{ Range Satisfaction Model } & \multicolumn{3}{|c|}{ EV Range Model } \\
\hline & $\begin{array}{l}\text { Odds } \\
\text { Ratio }\end{array}$ & Std Error & Prob>ChiSq & $\begin{array}{l}\text { Odds } \\
\text { Ratio }\end{array}$ & $\begin{array}{l}\text { Std } \\
\text { Error }\end{array}$ & Prob>ChiSq \\
\hline Intercept & & & $0.027^{\star \star}$ & & & $0.024 * \star$ \\
\hline Age & 1.007 & 0.010 & 0.469 & 1.007 & 0.010 & 0.461 \\
\hline Gender ( 1 male, 0 other) & 0.651 & 0.162 & 0.085 & 0.655 & 0.163 & $0.088^{\star}$ \\
\hline Education & 0.963 & 0.161 & 0.821 & 0.965 & 0.161 & 0.829 \\
\hline $\begin{array}{l}\text { Vehicle Ownership ( } 1 \\
\text { lease, } 0 \text { other) }\end{array}$ & 0.753 & 0.225 & 0.341 & 0.649 & 0.212 & 0.187 \\
\hline $\begin{array}{l}\text { Change in number of } \\
\text { household vehicles }\end{array}$ & 0.647 & 0.100 & $0.005^{\star \star \star}$ & 0.645 & 0.099 & $0.004 * \star \star$ \\
\hline $\begin{array}{l}\text { Change in number of } \\
\text { household people }\end{array}$ & 1.032 & 0.130 & 0.802 & 1.020 & 0.127 & 0.875 \\
\hline $\begin{array}{l}\text { Home type (detached 1, } \\
\text { other 0) }\end{array}$ & 0.653 & 0.198 & 0.159 & 0.647 & 0.196 & 0.151 \\
\hline $\begin{array}{l}\text { MPG of second household } \\
\text { vehicle }\end{array}$ & 0.972 & 0.008 & $<0.001^{\star \star \star}$ & 0.972 & 0.008 & $<0.001^{\star \star \star}$ \\
\hline Year of PEV adoption & 1.267 & 0.135 & $0.027 \star \star$ & 1.274 & 0.136 & 0.024 ** \\
\hline Commute distance & 0.982 & 0.009 & $0.039 *$ & 0.982 & 0.009 & $0.045^{\star \star}$ \\
\hline $\begin{array}{l}\text { Number of long distance } \\
\text { trips in past year }\end{array}$ & 0.991 & 0.015 & 0.537 & 0.989 & 0.015 & 0.488 \\
\hline Pro-technology attitude & 0.813 & 0.109 & 0.123 & 0.813 & 0.110 & 0.124 \\
\hline \multicolumn{7}{|l|}{$\begin{array}{l}\text { Satisfaction with vehicle } \\
\text { attributes: }\end{array}$} \\
\hline Safety & 0.865 & 0.106 & 0.237 & 0.883 & 0.110 & 0.317 \\
\hline $\begin{array}{l}\text { Vehicle Purchase Price } \\
\text { (including rebates, } \\
\text { discounts, etc.) }\end{array}$ & 0.942 & 0.103 & 0.584 & 0.926 & 0.103 & 0.488 \\
\hline Reliability & 1.048 & 0.134 & 0.712 & 1.039 & 0.133 & 0.765 \\
\hline Convenience of charging & 0.864 & 0.093 & 0.172 & 0.842 & 0.086 & $0.091^{*}$ \\
\hline $\begin{array}{l}\text { Refuelling/Recharging } \\
\text { costs }\end{array}$ & 0.987 & 0.138 & 0.924 & 0.981 & 0.137 & 0.889 \\
\hline Electric driving range & 0.892 & 0.082 & 0.216 & & & \\
\hline Electric Driving Range & & & & 0.997 & 0.002 & 0.172 \\
\hline
\end{tabular}




\begin{tabular}{|lllllll|}
\hline Level 2/ Level 1 & 0.467 & 0.081 & $<0.001^{\star \star *}$ & 0.489 & 0.086 & $0.006^{\star \star *}$ \\
\hline No Charging/ Level 1 & 0.734 & 0.128 & 0.417 & 0.749 & 0.132 & 0.450 \\
\hline No Charging/ Level 2 & 1.572 & 0.274 & 0.241 & 1.533 & 0.270 & 0.269 \\
\hline $\begin{array}{l}\text { Work charging dummy (1= } \\
\text { L1, L2, DC, 0=none) }\end{array}$ & 0.883 & 0.207 & 0.595 & 0.868 & 0.205 & 0.548 \\
\hline $\begin{array}{l}\text { Public charging dummy } \\
(1=\text { L2, DC, 0= L1, none) }\end{array}$ & 1.354 & 0.365 & 0.261 & 1.326 & 0.359 & 0.298 \\
\hline $\begin{array}{l}\text { Log likelihood } \\
\text { R-Square (U) }\end{array}$ & 282.68016 & & & & \\
\hline $\begin{array}{l}\text { Observations (or Sum of } \\
\text { Weights) }\end{array}$ & 0.1415 & & & 0.1421 & \\
\hline
\end{tabular}

\subsection{Modelling PHEV discontinuance}

Table 4 shows the results of the binary regression models for PHEVs. The model with PHEV range shows that the dummy variable for gender ( $1=$ male, $0=$ other) has an odds ratio of less than one and the odds of discontinuing PEHV adoption is $52.2 \%$ lower for males. This shows that non-male PHEV adopters are more likely to discontinue ownership compared to male adopters. The dummy variable for home type ( $1=$ detached house, 0 = other) correlates with a $76.6 \%$ decrease in odds of discontinuing PHEV adoption. This may be because those with a non-detached house are less likely to have access to charging at home, especially those living in apartments or condos.

A one point increase in the variable that measures satisfaction with the convenience of charging correlates with an $18.8 \%$ reduction in odds of discontinuing PHEV adoption. Satisfaction with refuelling/recharging costs is positively correlated, showing $45.5 \%$ increase in odds of discontinuing PHEV adoption for a one unit increase in satisfaction. This is counterintuitive but is perhaps explained by those that continued ownership moving from a PHEV which they were less satisfied with to a more efficient PEV. While those that discontinued PHEV adoption where satisfied with this attribute this was not sufficient enough for them to continue with owning a PHEV.

Having no charging rather than level 2 charging at home increases the odds of discontinuing PEV adoption by 2.193 times. No charging compared to level 1 charging has no effect. Having used public level 2 public charging has an odds ratio of 0.549 , showing that the use of public chargers decreases the odds of discontinuing PHEV adoption. Those who discontinued owning a PHEV may have been less 
motivated to charge their vehicles, tending to drive them more as a hybrid without first using the electric range.

The second model, where satisfaction with PHEV electric driving range is substituted with actual electric driving range, finds that the same variables correlate with PHEV discontinuance. In this model driving range is not significant, therefore neither satisfaction with range nor actual range are correlated with PHEV discontinuance.

The results differ from the BEV models in a few areas. Only two variables are significant in both models, discontinuance of PHEVs and BEVs is correlated with dissatisfaction with the convenience of charging and not being male.

Table 4: Binary logistic regression models for PHEV discontinuance (where 1= discontinued PHEV ownership, $0=$ continued PHEV ownership). The table shows two models, one with Satisfaction with PHEV range as an independent variable, and a second with EV driving range $\left({ }^{*}=<0.1, * *=<0.05, * * *=\right.$ $<0.01)$. 


\begin{tabular}{|c|c|c|c|c|c|c|}
\hline \multirow[b]{2}{*}{ Term } & \multicolumn{3}{|c|}{ Range Satisfaction } & \multicolumn{3}{|c|}{ EV Range } \\
\hline & $\begin{array}{l}\text { Odds } \\
\text { Ratio }\end{array}$ & Std Error & Prob>ChiSq & $\begin{array}{l}\text { Odds } \\
\text { Ratio }\end{array}$ & Std Error & Prob>ChiSq \\
\hline Intercept & & & 0.118 & & & 0.152 \\
\hline Age & 0.994 & 0.011 & 0.600 & 0.995 & 0.011 & 0.639 \\
\hline Gender ( 1 male, 0 other) & 0.469 & 0.142 & $0.012^{\star \star}$ & 0.478 & 0.146 & $0.016 * \star$ \\
\hline Education & 0.886 & 0.165 & 0.516 & 0.877 & 0.164 & 0.485 \\
\hline $\begin{array}{l}\text { Vehicle Ownership ( } 1 \\
\text { lease, } 0 \text { other) }\end{array}$ & 1.312 & 0.451 & 0.430 & 1.336 & 0.461 & 0.401 \\
\hline $\begin{array}{l}\text { Change in number of } \\
\text { household vehicles }\end{array}$ & 0.774 & 0.135 & 0.141 & 0.768 & 0.133 & 0.129 \\
\hline $\begin{array}{l}\text { Change in number of } \\
\text { household people }\end{array}$ & 1.014 & 0.164 & 0.932 & 1.029 & 0.166 & 0.859 \\
\hline $\begin{array}{l}\text { Home type (detached 1, } \\
\text { other 0) }\end{array}$ & 0.330 & 0.118 & $0.002 * \star \star$ & 0.334 & 0.120 & $0.002^{\star \star \star}$ \\
\hline MPG of second vehicle & 0.990 & 0.006 & 0.119 & 0.991 & 0.006 & 0.128 \\
\hline Year of PEV adoption & 0.827 & 0.101 & 0.120 & 0.839 & 0.103 & 0.154 \\
\hline Commute distance & 0.986 & 0.010 & 0.157 & 0.986 & 0.010 & 0.147 \\
\hline $\begin{array}{l}\text { Number of long distance } \\
\text { trips in past year }\end{array}$ & 1.008 & 0.014 & 0.592 & 1.007 & 0.014 & 0.600 \\
\hline Pro-technology attitude & 0.979 & 0.167 & 0.902 & 0.968 & 0.167 & 0.848 \\
\hline \multicolumn{7}{|l|}{$\begin{array}{l}\text { Satisfaction with vehicle } \\
\text { attributes: }\end{array}$} \\
\hline Safety & 0.934 & 0.147 & 0.664 & 0.928 & 0.146 & 0.636 \\
\hline $\begin{array}{l}\text { Vehicle Purchase Price } \\
\text { (including rebates, } \\
\text { discounts, etc.) }\end{array}$ & 0.834 & 0.105 & 0.149 & 0.850 & 0.105 & 0.187 \\
\hline Reliability & 0.832 & 0.130 & 0.237 & 0.836 & 0.130 & 0.247 \\
\hline Convenience of charging & 0.785 & 0.099 & $0.054^{\star}$ & 0.812 & 0.095 & $0.075^{\star}$ \\
\hline $\begin{array}{l}\text { Refuelling/Recharging } \\
\text { costs }\end{array}$ & 1.430 & 0.253 & $0.043^{\star}$ & 1.455 & 0.258 & 0.034 ** \\
\hline Electric driving range & 1.092 & 0.128 & 0.454 & & & \\
\hline Electric Driving Range & & & & 0.999 & 0.006 & 0.876 \\
\hline
\end{tabular}




\begin{tabular}{|lllllll|}
\hline Level 2/ Level 1 & 0.697 & 0.127 & 0.230 & 0.700 & 0.129 & 0.240 \\
\hline No Charging/ Level 1 & 1.490 & 0.272 & 0.302 & 1.535 & 0.282 & 0.267 \\
\hline No Charging/ Level 2 & 2.137 & 0.390 & $0.073^{\star}$ & 2.193 & 0.403 & $0.063^{\star}$ \\
\hline $\begin{array}{l}\text { Work charging dummy } \\
(1=\text { L1, L2, DC, 0=none) }\end{array}$ & 0.910 & 0.255 & 0.735 & 0.897 & 0.251 & 0.696 \\
\hline $\begin{array}{l}\text { Public charging dummy } \\
(1=\text { L2, DC, 0= L1, none) }\end{array}$ & 0.549 & 0.176 & $0.061^{*}$ & 0.554 & 0.177 & $0.064^{*}$ \\
\hline $\begin{array}{l}\text { Log likelihood } \\
\text { R-Square (U) }\end{array}$ & 223.61826 & & & & \\
\hline $\begin{array}{l}\text { Observations (or Sum of } \\
\text { Weights) }\end{array}$ & 0.1083 & & & 0.1095 & \\
\hline
\end{tabular}

\section{Conclusion}

Discontinuance will slow electric vehicle market growth and make reaching 100\% PEV sales impossible. In California, 17\% of BEV and 21\% of PHEV adopters who purchased their PEV between 2012 and 2018 discontinued PEV ownership. Factors associated with discontinuance of BEVs and PHEVs are dissatisfaction with charging convenience, a lack of level 2 charging at home, and not being male; additional factors associated with discontinuance of just BEVs but not PHEVs are having preferences for vehicles with lower efficiencies and being a later adopter. The reasons why female PEV buyers are more likely to discontinue ownership is not clear, similarly the reason why so few PEV adopters are female remains unclear [53]. More research is needed on this topic to understand how to encourage female drivers adopt and continue to own PEVs. Even after initially overcoming the barrier of the different refuelling style, some adopters decided not to continue with PEV ownership for the same reasons many do not purchase one in the first place. The fact that discontinuance is not correlated with vehicle range but is correlated with access to charging and the convenience of charging intuitively makes sense. The way in which a PEV is charged has not changed, whereas vehicle range has been increasing since PHEVs and BEVs were introduced. PEV adopters have the option to purchase longer-range vehicles, whereas they cannot yet purchase a vehicle that is charged differently (e.g., though inductive charging). Finally, the increasing odds of discontinuing BEV adoption with later year of purchase is concerning. This trend is occurring concurrently with more PEV adopters reporting they would not purchase their PEV without incentives year on year [52] and with buyers' socio-demographics changing each year, with more moderate income buyers adopting a PEV [50]. This will mean the introduction of BEVs and PHEVs will face more challenges overtime, will not get easier as some hope, and will still require policy support. 
Initial adoption of a PEV by a consumer does not ensure that they will continue ownership. Most existing research investigates how to increase rates of first-time adoption of PEVs through incentives, infrastructure, and other policies. We hope to encourage more research into understanding how to ensure PEV adopters become permanent adopters and do not abandon a PEV for vehicles that are less energy efficient.

\section{Declarations}

\section{Acknowledgements}

Thanks to Matthew Favetti for programming and supporting the development of the questionnaire survey used in this study. This analysis conducted in study was funded by a grant from the National Center for Sustainable Transportation (NCST), supported by USDOT through the University Transportation Centers programme. The questionnaire surveys were funded by the California Air Resources Board (CARB). The authors thank NCST, USDOT, and CARB for their support of this project.

\section{Data avaliability}

The questionnaire survey data used in this study can be obtained by contacting the corresponding author via email at shardman@ucdavis.edu

\section{Ethics \& Consent}

The University of California, Davis Institutional Review Board (IRB) Administration granted approval this study. The study followed all relevant ethical regulations in the study of human subjects for social research. All participants consented to participating in the questionnaire survey.

\section{References}

[1] Plötz P, Axsen J, Funke SA, Gnann T. Designing car bans for sustainable transportation. Nat Sustain. Springer US; 2019;2(7):534-6.

[2] Rogers EM. Diffusion of Innovations. 5th Editio. New York: Free Press; 2003.

[3] Egbue O, Long S. Barriers to widespread adoption of electric vehicles: An analysis of consumer attitudes and perceptions [Internet]. Vol. 48, Energy Policy. 2012. p. 717-29. Available from: http://dx.doi.org/10.1016/j.enpol.2012.06.009

[4] Schneidereit T, Franke T, Günther M, Krems JF. Does range matter? Exploring perceptions of electric vehicles with and without a range extender among potential early adopters in Germany. Energy Res Soc Sci [Internet]. Elsevier Ltd; 2015;8:198-206. 
[5] Campbell AR, Ryley T, Thring R. Identifying the early adopters of alternative fuel vehicles: A case study of Birmingham, United Kingdom. Transp Res Part A Policy Pract [Internet]. Elsevier Ltd; 2012 Oct [cited 2013 Nov 21];46(8):1318-27.

[6] Kurani KS, Turrentine T, Sperling D. Demand for electric vehicles in hybrid households: an exploratory analysis. Transp Policy. 1994;1(4):244-56.

[7] Hidrue M, Parsons G, Kempton W, Gardner M. Willingness to pay for electric vehicles and their attributes. Resour Energy Econ [Internet]. Elsevier B.V.; 2011 Sep [cited 2014 Sep 15];33(3):686-705.

[8] Graham-Rowe E, Gardner B, Abraham C, Skippon S, Dittmar H, Hutchins R, et al. Mainstream consumers driving plug-in battery-electric and plug-in hybrid electric cars: A qualitative analysis of responses and evaluations. Transp Res Part A Policy Pract [Internet]. Elsevier Ltd; 2012 Jan [cited 2014 Oct 2];46(1):140-53.

[9] Peters A, Dütschke E. How do Consumers Perceive Electric Vehicles? A Comparison of German Consumer Groups. J Environ Policy Plan [Internet]. 2014 Feb 5 [cited 2014 Oct 22];16(3):359-77.

[10] Helveston JP, Liu Y, Feit EM, Fuchs E, Klampfl E, Michalek JJ. Will subsidies drive electric vehicle adoption? Measuring consumer preferences in the U.S. and China. Transp Res Part A Policy Pract [Internet]. Elsevier Ltd; 2015;73:96-112.

[11] Axsen J, Kurani KS. Hybrid, plug-in hybrid, or electric-What do car buyers want? Energy Policy [Internet]. Elsevier; 2013;61:532-43.

[12] Plötz P, Gnann T. Who should buy electric vehicles? - The potential early adopter from an economical perspective. ECEEE. 2011;(2009):1073-80.

[13] Bühler F, Cocron P, Neumann I, Franke T, Krems JF. Is EV experience related to EV acceptance? Results from a German field study. Transp Res Part F Traffic Psychol Behav [Internet]. 2014 Jul [cited 2014 Oct 6];25:34-49.

[14] Skippon S, Garwood M. Responses to battery electric vehicles: UK consumer attitudes and attributions of symbolic meaning following direct experience to reduce psychological distance. Transp Res Part D Transp Environ [Internet]. Elsevier Ltd; 2011;16(7):525-31.

[15] Ensslen A, Paetz A-G, Babrowski S, Jochem P, Fichtner W. On the Road to an Electric Mobility Mass Market--How Can Early Adopters be Characterized? In: Fornahl D, Hülsmann M, editors. Markets and Policy Measures in the Evolution of Electric Mobility [Internet]. Cham: Springer International Publishing; 2016. p. 21-51.

[16] Julius P, Plötz P, Dütschke E. How to trigger mass market adoption of electric vehicles? Factors predicting interest in electric vehicles in Germany. 2016. Available from 
[17] Plötz P, Schneider U, Globisch J, Dütschke E. Who will buy electric vehicles? Identifying early adopters in Germany. Transp Res Part A Policy Pract [Internet]. 2014 Sep [cited 2014 Sep 24];67:96-109.

[18] Mohamed M, Higgins C, Ferguson M, Kanaroglou P. Identifying and characterizing potential electric vehicle adopters in Canada : A two-stage modelling approach. Transp Policy [Internet]. Elsevier; 2016;52:100-12.

[19] Westin K, Jansson J, Nordlund A. The importance of socio-demographic characteristics, geographic setting, and attitudes for adoption of electric vehicles in Sweden. Travel Behav Soc [Internet]. Elsevier; 2018;13(July):118-27.

[20] Figenbaum E, Kolbenstvedt M. Learning from Norwegian Battery Electric and Plug-in Hybrid Vehicle Users. 2016.

[21] Hardman S, Shiu E, Steinberger-Wilckens R. Comparing High-End and Low-End Early Adopters of Battery Electric Vehicles. Transp Res Part A Policy Pract. 2016;88:40-57.

[22] Hardman S, Tal G. Exploring the decision to adopt a high-end battery electric vehicle: The role of financial and non-financial motivations. Transp Res Rec J Transp Res Board. 2016;16-1783.

[23] Axsen J, Cairns J, Dusyk N, Goldberg S. What drives the Pioneers? Applying lifestyle theory to early electric vehicle buyers in Canada. Energy Res Soc Sci [Internet]. Elsevier; 2018;44(April):17-30.

[24] Bunch DS, Bradley M, Golob TF, Kitamura R, Occhiuzzo GP. Demand for Clean-Fuel Vehicles in California: A Discrete-Choice Stated Preference Pilot Project. Transp Res Part A Policy Pract. 1993;27(3):237-53.

[25] Axsen J, Bailey J, Andrea M. Preference and lifestyle heterogeneity among potential plug-in electric vehicle buyers. Energy Econ. Elsevier B.V.; 2015;50:190-201.

[26] Gnann T, Plötz P, Funke S, Wietschel M. What is the market potential of plug-in electric vehicles as commercial passenger cars? A case study from Germany. Transp Res Part D Transp Environ [Internet]. Elsevier Ltd; 2015;37:171-87.

[27] Carley S, Krause RM, Lane BW, Graham JD. Intent to purchase a plug-in electric vehicle: A survey of early impressions in large US cites. Transp Res Part D Transp Environ [Internet]. Elsevier Ltd; 2013 Jan [cited 2013 May 22];18:39-45.

[28] Schuitema G, Anable J, Skippon S, Kinnear N. The role of instrumental, hedonic and symbolic attributes in the intention to adopt electric vehicles. Transp Res Part A Policy Pract [Internet]. 2013;48:3949.

[29] White L V, Sintov ND. You are what you drive: Environmentalist and social innovator symbolism drives electric vehicle adoption intentions. Transp Res Part A [Internet]. Elsevier Ltd; 2017;99:94-113. 
[30] Higueras-castillo E, Molinillo S, Coca-stefaniak JA, Li F. Perceived Value and Customer Adoption of Electric and Hybrid Vehicles. Sustainability. 2019;1-15.

[31] Choi D, Johnson KKP. Influences of environmental and hedonic motivations on intention to purchase green products: An extension of the theory of planned behavior. Sustain Prod Consum [Internet]. Elsevier B.V.; 2019;18:145-55.

[32] Huang X, Ge J. Electric vehicle development in Beijing: An analysis of consumer purchase intention. J Clean Prod [Internet]. Elsevier Ltd; 2019;216:361-72.

[33] Liu Y, Ouyang Z, Cheng P. Predicting consumers ' adoption of electric vehicles during the city smog crisis: An application of the protective action decision model. J Environ Psychol [Internet]. Elsevier Ltd; 2019;64(September 2018):30-8.

[34] Rezvani Z, Jansson J, Bodin J. Advances in consumer electric vehicle adoption research: A review and research agenda. Transp Res Part D Transp Environ [Internet]. Elsevier Ltd; 2015;34:122-36.

[35] Hardman S, Tal G. Exploring the Decision to Adopt a High-End Battery Electric Vehicle Role of Financial and Nonfinancial Motivations. Transp Res Rec J Transp Res Board. 2016;20-7.

[36] Lane B, Sherman C, Sperl J, Krause R, Carley S, Graham J. Beyond Early Adopters of Plug-in Electric Vehicles? Evidence from Fleet and Household Users in Indianapolis. Transportation Research Board 2014 Annual Meeting; 2014. 1-18 p.

[37] Caperello N, Tyreehageman J, Davies J. I am not an environmental wacko! Getting from early plugin vehicle owners to potential later buyers. Transp Res Board 2015 Annu Meet. 2015;

[38] Egbue O, Long S. Barriers to widespread adoption of electric vehicles: An analysis of consumer attitudes and perceptions. Energy Policy [Internet]. Elsevier; 2012 Sep [cited 2014 Jul 11];48(2012):71729.

[39] Turrentine T, Dahlia G, Lentz A, Woodjack J. The UC Davis MINI E Consumer Study. Institute of Transportation Studies, University of California, Davis, Research Report; 2011.

[40] Hardman S, Chandan A, Tal G, Turrentine T. The Effectiveness of Financial Purchase Incentives for Battery Electric Vehicles - A Review of the Evidence (Article Under Review). Renew Sustain Energy Rev. 2017;

[41] Hardman S. Understanding the impact of reoccurring and non-financial incentives on plug-in electric vehicle adoption - A review. Transp Res Part A Policy Pract. Elsevier Ltd; 2019 Jan;119:1-14.

[42] Jabbari P, Chernicoff W, Mackenzie D. Analysis of Electric Vehicle Purchaser Satisfaction and Rejection Reasons. Transp Res Rec J Transp Res Board. 2017; 
[43] Adepetu A, Keshav S. The relative importance of price and driving range on electric vehicle adoption: Los Angeles case study. Transportation (Amst). Springer US; 2017;44(2):353-73.

[44] She Z, Sun Q, Ma J, Xie B. What are the barriers to widespread adoption of battery electric vehicles? A survey of public perception in Tianjin , China. Transp Policy [Internet]. Elsevier Ltd; 2017;56(March):2940.

[45] Vassileva I, Campillo J. Adoption barriers for electric vehicles: Experiences from early adopters in Sweden. Energy [Internet]. Elsevier Ltd; 2017;120:632-41.

[46] Franke T, Neumann I, Bühler F, Cocron P, Krems JF. Experiencing Range in an Electric Vehicle: Understanding Psychological Barriers. Appl Psychol. 2012;61(3):368-91.

[47] Dumortier J, Siddiki S, Carley S, Cisney J, Krause RM, Lane BW, et al. Effects of providing total cost of ownership information on consumers' intent to purchase a hybrid or plug-in electric vehicle. Transp Res Part A Policy Pract [Internet]. Elsevier Ltd; 2015;72:71-86.

[48] Kim S. Does Driving Range of Electric Vehicles Influence Electric Vehicle Adoption? Sustainability. 2017;

[49] Berkeley N, Jarvis D, Jones A. Analysing the take up of battery electric vehicles: An investigation of barriers amongst drivers in the UK. Transp Res Part D [Internet]. Elsevier; 2018;63(June):466-81.

[50] Lee JH, Hardman S, Tal G. Who is buying electric vehicles in California? Characterising early adopter heterogeneity and forecasting market diffusion. Energy Res Soc Sci. 2019;

[51] Chakraborty D, Bunch DS, Lee JH, Tal G. Demand drivers for charging infrastructure-charging behavior of plug-in electric vehicle commuters. Transp Res Part D Transp Environ. Elsevier Ltd; 2019 Nov;76:255-72.

[52] Jenn A, Lee JH, Hardman S, Tal G. An in-depth examination of electric vehicle incentives: consumer heterogeneity and changing response over time. Transp Res Part A Policy Pract. 2020;132:97-109.

[53] Kurani KS, Caperello N, TyreeHageman J. Are we Hardwiring Gender Differences into the Market for Plug-in Electric Vehicles. 2018;(March).

\section{Figures}



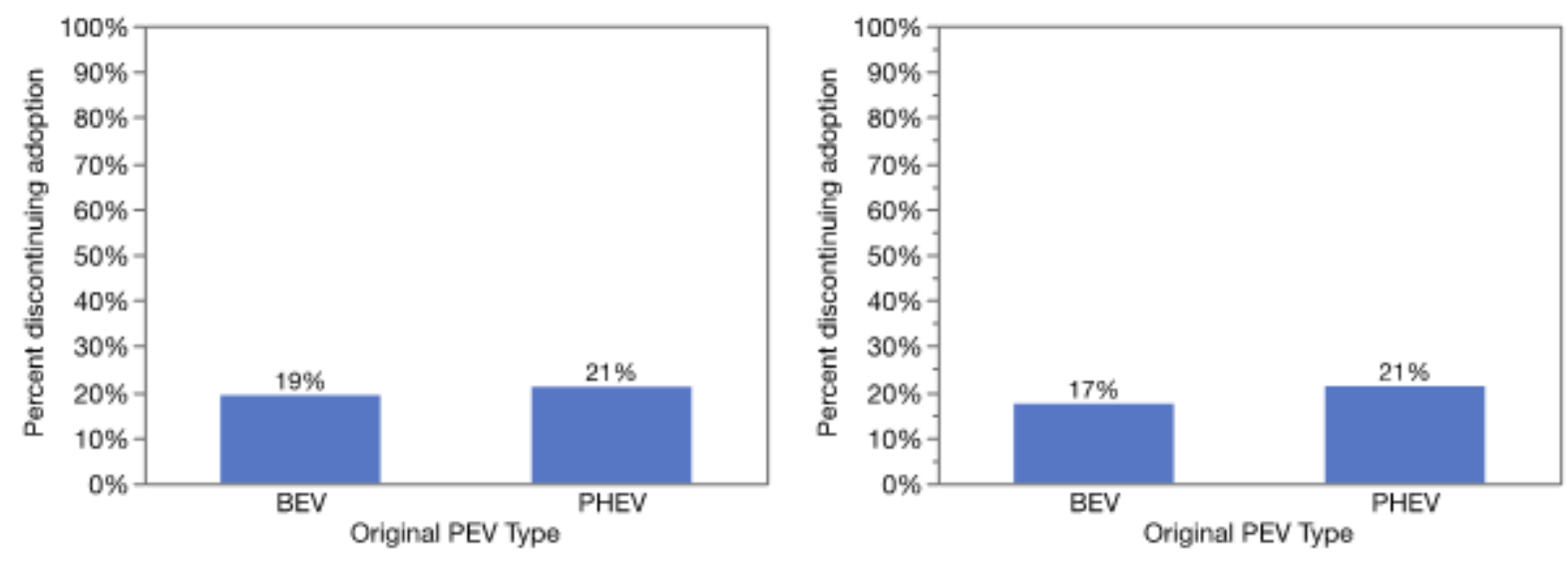

\section{Figure 1}

Percent of PHEV and BEV adopters who discontinued ownership in the sample (left) and the weighted percent (see Appendix 1 for weights) of PHEV and BEV adopters in the sample (right) $(n=1842)$.

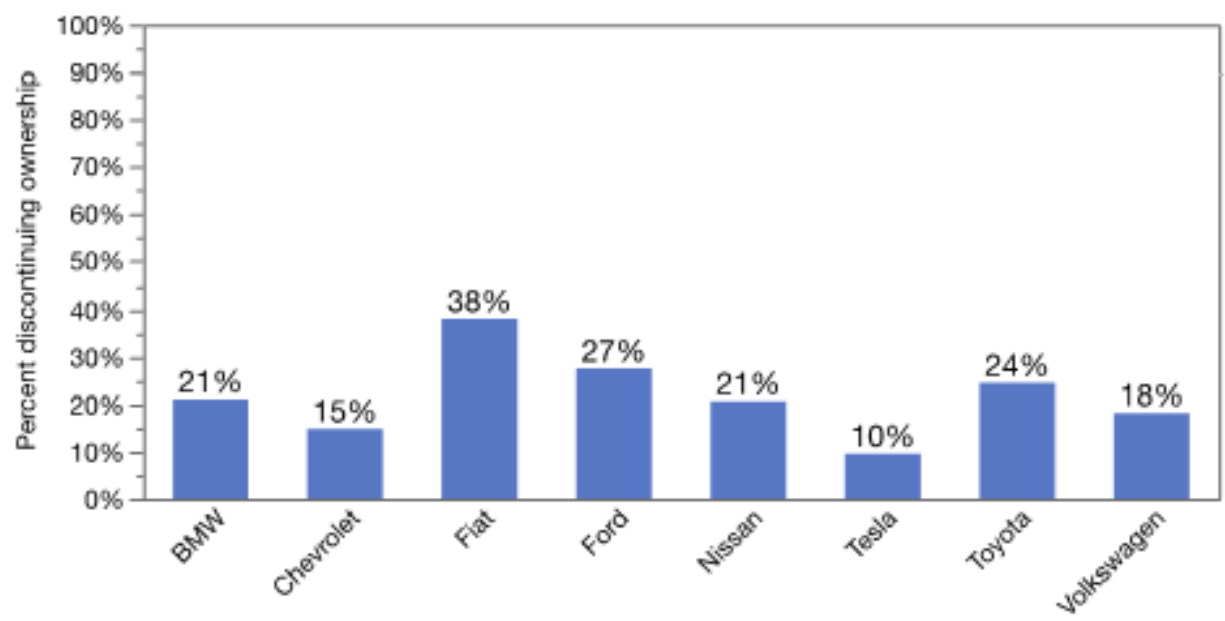

Make of original PEV

\section{Figure 2}

Percent of PEV adopters who discontinued ownership by make of original PEV owned (note: we exclude less common vehicles within the sample for this graph, see appendix 2 for a table of all vehicles in the whole sample, and the percentage of each that discontinued PEV ownership) ( $n=1738)$. 


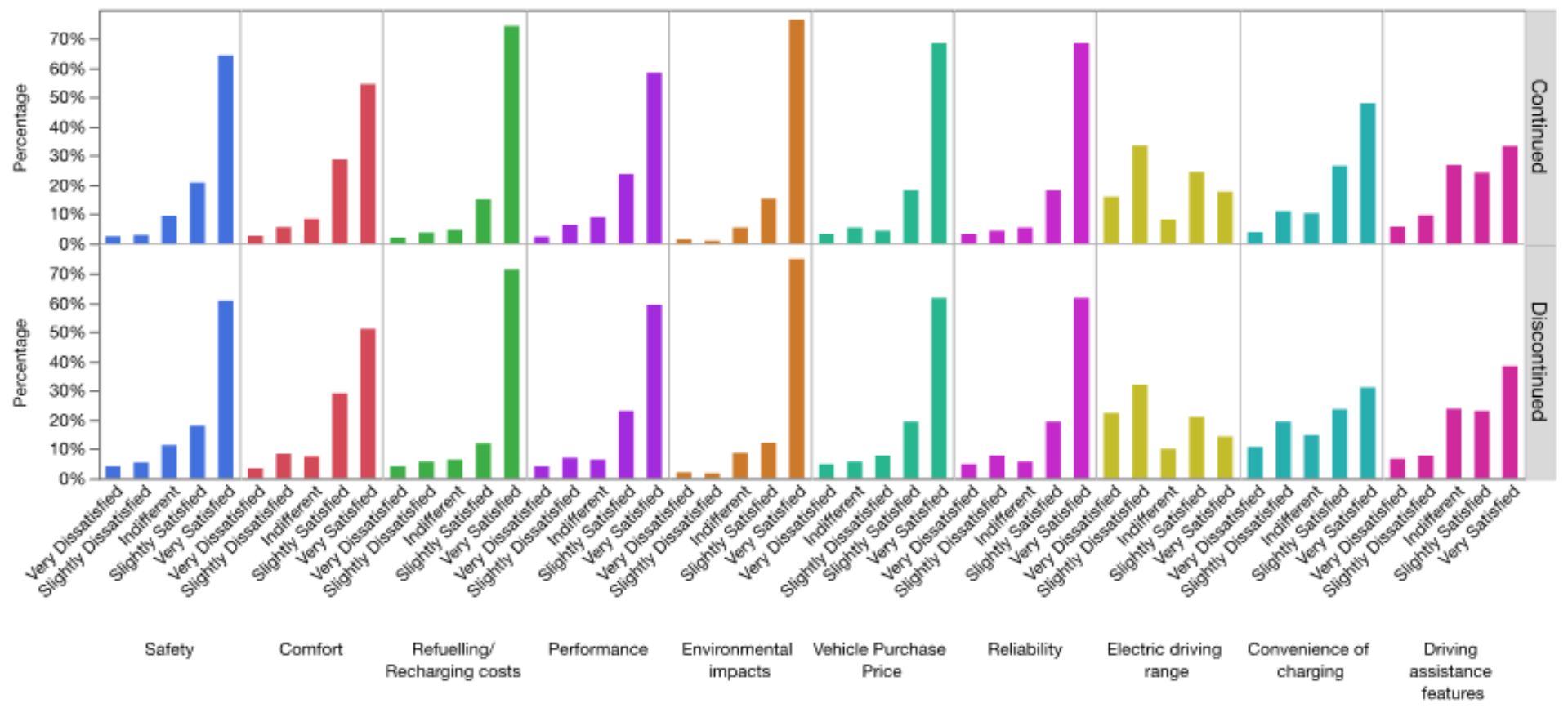

\section{Figure 3}

Satisfaction with previous PEV for those who continued PEV ownership (top) and those who discontinued PEV ownership (bottom). The figure represents answers to the question "Thinking about your \{make and model previous PEV\}, how satisfied were you with the vehicle for each of the below?" for all 10 attributes shown in the chart $(n=1672)$.

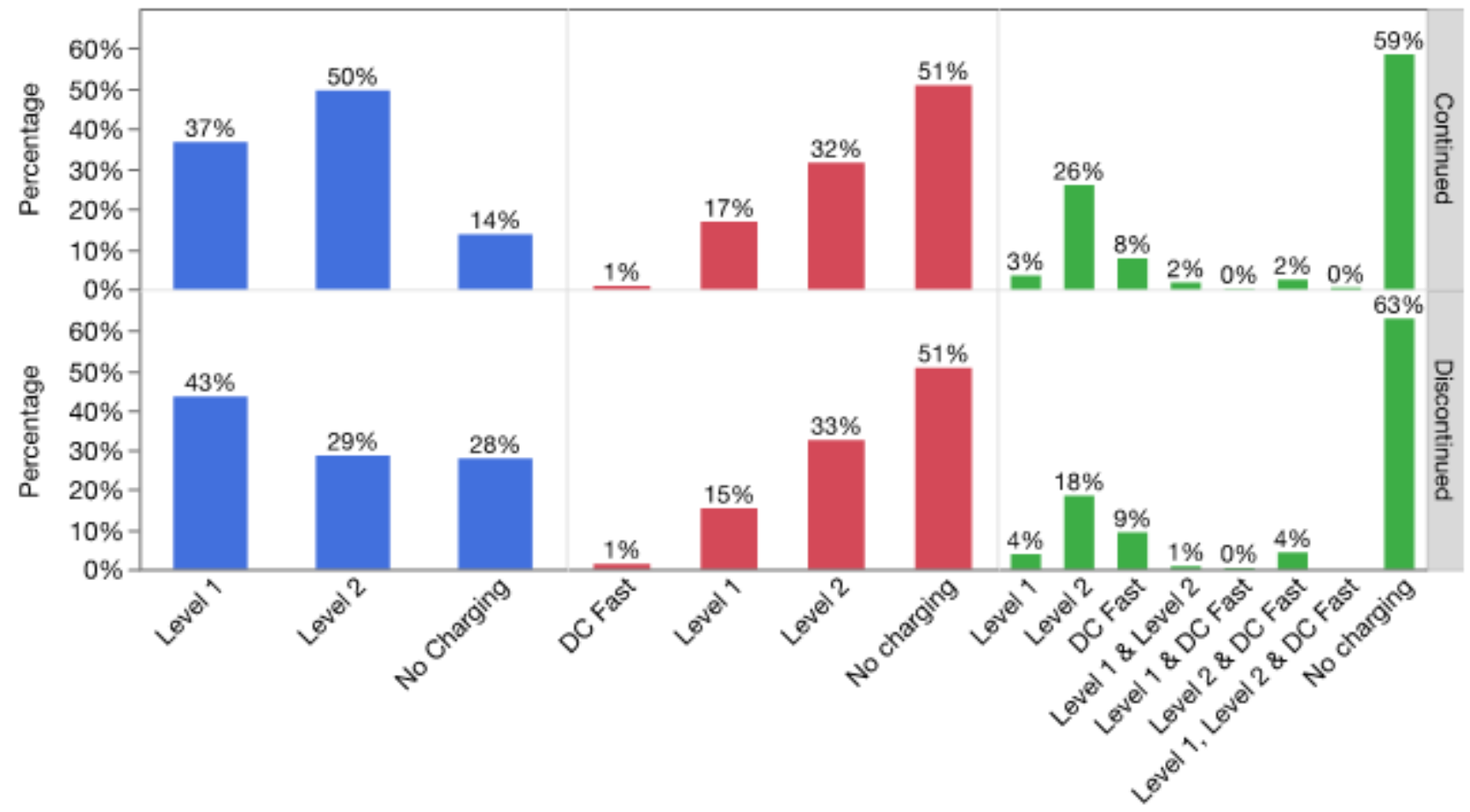


Figure 4

Access to charging at home (blue) and work (red), including charging level, and whether respondents report having used public charging, and the levels of charging they report using (green)-for those that continued (top) and discontinued (bottom) PEV ownership.

\section{Supplementary Files}

This is a list of supplementary files associated with this preprint. Click to download.

- SupplementaryInformation.docx 